\title{
Multiple coping strategies maintain stability of a small mammal population in resource-restricted environments
}

\author{
Ann Polyakov ${ }^{1}$, William Tietje ${ }^{1}$, Arjun Srivathsa ${ }^{2}$, Virginie Rolland ${ }^{3}$, James Hines ${ }^{4}$, and \\ Madan $\mathrm{Oli}^{2}$ \\ ${ }^{1}$ University of California Berkeley \\ ${ }^{2}$ University of Florida \\ ${ }^{3}$ Arkansas State University \\ ${ }^{4}$ USGS
}

January 20, 2021

\begin{abstract}
In semi-arid environments, aperiodic rainfall pulses determine cycles of plant production and resource availability for higher trophic levels, creating strong bottom-up regulation. The influence of climatic factors on population vital rates often shapes the dynamics of small mammal populations in such resource-restricted environments. Using a 21-year biannual capture-recapture dataset (1993 to 2014), we examined the impacts of climatic factors on the population dynamics of the brush mouse (Peromyscus boylii) in semi-arid oak woodland of coastal-central California. We applied Pradel's temporal symmetry model to estimate capture probability $(p)$, apparent survival $(\varphi)$, recruitment (f), and realized population growth rate $(\lambda)$ of the brush mouse, and examined the effects of temperature, rainfall, and El Niño on these demographic parameters. The population was stable during the study period with a monthly realized population growth rate of $0.993 \pm \mathrm{SE} 0.032$, but growth varied over time from $0.680 \pm$ 0.054 to $1.450 \pm 0.083$. Monthly survival estimates averaged $0.817 \pm 0.005$ and monthly recruitment estimates averaged 0.175 \pm 0.038 . Survival probability and realized population growth were positively correlated with rainfall and negatively correlated with temperature. In contrast, recruitment was negatively correlated with rainfall and positively correlated with temperature. Brush mice maintained their population through multiple coping strategies, investing in high recruitment during warmer and drier periods and allocating more energy towards survival during cooler and wetter conditions. Although climatic change in coastal-central California will favor recruitment over survival, varying strategies may serve as a mechanism by which brush mice maintain resilience in the face of climate change. Our results indicate that rainfall and temperature are both important drivers of brush mouse population dynamics and will play a significant role in predicting the future viability of brush mice under a changing climate.
\end{abstract}

\section{Hosted file}

Polyakov et al. 2020 Multiple coping strategies.pdf available at https://authorea.com/users/ 390743/articles/504969-multiple-coping-strategies-maintain-stability-of-a-small-mammalpopulation-in-resource-restricted-environments 